\title{
EL CASO PALAMARA IRIBARNE VS. CHILE
}

Luppy Aguirre Bravo*

\section{Introducción}

En noviembre del año 2005, la Corte Interamericana de Derechos Humanos condenó al Estado Chileno tras una denuncia interpuesta por el ciudadano Humberto Palamara Iribarne. El asunto fue sometido a conocimiento de la Corte, por parte de la Comisión Interamericana de Derechos Humanos, en abril de 2004. El presente comentario da cuenta de lo resuelto en definitiva, por la Corte Interamericana y de las acciones implementadas por el Estado de Chile a fin de dar cumplimiento a lo sentenciado por dicho tribunal internacional.

\section{Antecedentes del caso Palamara vs. Chile}

Humberto Palamara Iribarne, funcionario civil a contrata de la Armada de Chile, en la ciudad de Punta Arenas, intentó publicar el año 1993 el libro "Etica y Servicios de Inteligencia”, el cual trataba aspectos relacionados con la inteligencia militar y la necesidad de adecuarla a ciertos parámetros éticos.

Informado el mando de la Armada de Chile sobre la existencia del libro que pretendía publicar, ésta intentó -con éxito- impedir su circulación, argumentando que el material ponía en riesgo la seguridad y la defensa nacional. Se le ordenó detener la publicación y comercialización del texto, lo cual fue rechazado por el Sr. Palamara, en atención a que éste era fruto de sus conocimientos en la materia y no contenía ningún antecedente que pudiese ser considerado riesgoso para la seguridad nacional. Se le ordenó además hacer entrega de los ejemplares ya editados, que se encontraban en su poder y en la imprenta, lo cual tampoco realizó.

Ante dichas acciones, y a fin de impedir la divulgación del material elaborado por el Sr. Palamara, se instruyeron tres procesos criminales en su contra ante el Juzgado Naval de Magallanes, uno por el delito de incumplimiento de órdenes y deberes militares contemplado en el artículo 299 No 3 del Código de Justicia Militar ${ }^{1}$ y dos por el delito de desobediencia ${ }^{2}$ contemplado en los artículos

\footnotetext{
* Abogado, Licenciada en Ciencias Jurídicas y Sociales de la Universidad de Chile. Investigadora del Centro de Estudios de la Justicia de la Facultad de Derecho de la Universidad de Chile.

${ }^{1}$ El fundamento de la denuncia dice relación con la negativa del Sr. Palamara de cumplir la orden en torno a no publicar el libro e incumplir lo dispuesto en el artículo 89 de la Ordenanza de la Armada $\mathrm{N}^{\circ} 487$ de fecha 21 de abril de 1988, que consagra la prohibición respecto de "todo miembro de la Armada o persona que se encuentre a su servicio, [de] publicar o dar facilidades para
} 
Aguirre - El caso Palamara

336 y 337, del mismo cuerpo legal, delitos por los cuales fue detenido, procesado, sometido a prisión preventiva y en definitiva, condenado ${ }^{3}$.

Durante la sustanciación de tales causas, además de ser el Sr. Palamara expulsado de la Armada, se procedió a la incautación de los ejemplares del libro, los originales del texto, un disco que contenía el texto íntegro y la matricería electroestática, material que se encontraba en la imprenta encargada de la edición de la publicación. Asimismo, se eliminó el texto íntegro del libro contenido en el disco duro de la computadora personal que se encontraba en el domicilio del señor Palamara y a la incautación de los libros que se encontraban en dicho domicilio.

En el desarrollo de los diversos procesos a los cuales fue sometido el Sr. Palamara, su defensa alegó en todas las instancias que, el impedir la publicación y distribución del texto creado por el Sr. Palamara, atentaba contra su libertad de pensamiento y expresión, y que la Justicia Militar era incompetente para conocer de los hechos que se le imputaban, por cuanto él no había cometido delito alguno de carácter militar, ni poseía la calidad de militar de conformidad a lo establecido en el artículo $6^{\circ}$ del CJM, puesto que era un funcionario civil a contrata, categoría no inclusa en dicha norma. Estas argumentaciones, como se ha señalado, fueron rechazadas en todas las instancias.

Por estos hechos, el 16 de enero de 1996, el Centro por la Justicia y el Derecho Internacional (CEJIL), con sede en Buenos Aires, Argentina, presentó una denuncia ante la Comisión Interamericana de Derechos Humanos. El caso fue

que se publiquen en prensa, artículos que envuelvan una crítica a los servicios de la Armada, de organismos públicos o de gobierno".

${ }^{2}$ Estos ilícitos le fueron imputados: uno por negarse a hacer entrega de los ejemplares ya editados y que se encontraban en su poder y en la imprenta y otro, tras conceder una conferencia de prensa relativa al proceso que le estaba siendo instruido por incumplimiento de deberes militares. Por este último hecho, además se instruyó una investigación criminal ante la justicia ordinaria por el delito de desacato contemplado en el artículo 264 N³ del Código Penal en relación a los artículos 265 y 266 del mismo cuerpo legal. Tras declararse incompetente, los antecedentes pasaron a la judicatura castrense, la cual lo condenó, en definitiva a la pena de 61 días de presidio menor en su grado mínimo.

${ }^{3}$ Por el delito de incumplimiento de deberes militares en primera instancia fue condenado a 61 días de presidio militar menor en su grado mínimo, pérdida del estado militar, suspensión de cargo público durante el tiempo de duración de las condenas, el comiso de los 900 ejemplares del libro incautados y de sus respaldos y, costas de la causa. Por los delitos de desobediencia fue condenado a 2 penas, una de 541 días de reclusión militar menor en su grado mínimo por el ilícito contemplado en el artículo 337 del Código de Justicia Militar (CJM) y otra de 61 días de presidio militar menor en su grado mínimo por el ilícito contemplado en el artículo 336, del mismo cuerpo legal. La Corte Marcial, conociendo de la causa por vía de apelación, lo absolvió del delito de desobediencia contemplado en el artículo 336 del CJM, redujo su pena a 61 días por el delito de desobediencia contemplado en el artículo 337 del CJM y lo eximió de la pena de pérdida del estado militar. En lo demás el fallo fue confirmado. La Corte Suprema rechazó el recurso de casación interpuesto por la defensa del Sr. Palamara. 
admitido por dicha Comisión en octubre del año 2001.

La denuncia señalaba que el Estado de Chile era responsable por la violación de los derechos consagrados en los artículos 7 (Libertad Personal) , 8.2 (Garantías Judiciales), 13 (Libertad de Pensamiento y de Expresión) y 21 (Derecho a la Propiedad Privada) de la Convención Americana sobre Derechos Humanos, en relación con las obligaciones establecidas en los artículos 1.1 (Obligación de Respetar los Derechos) y 2 (Deber de Adoptar Disposiciones de Derechos Interno $)^{4}$ de la misma convención, al condenar a Humberto Palamara por los

\footnotetext{
${ }^{4}$ Artículo 1. Obligación de Respetar los Derechos: 1. Los Estados Partes en esta Convención se comprometen a respetar los derechos y libertades reconocidos en ella y a garantizar su libre y pleno ejercicio a toda persona que esté sujeta a su jurisdicción, sin discriminación alguna por motivos de raza, color, sexo, idioma, religión, opiniones políticas o de cualquier otra índole, origen nacional o social, posición económica, nacimiento o cualquier otra condición social.
}

Artículo 2. Deber de Adoptar Disposiciones de Derecho Interno: Si el ejercicio de los derechos y libertades mencionados en el artículo 1 no estuviere ya garantizado por disposiciones legislativas o de otro carácter, los Estados Partes se comprometen a adoptar, con arreglo a sus procedimientos constitucionales y a las disposiciones de esta Convención, las medidas legislativas o de otro carácter que fueren necesarias para hacer efectivos tales derechos y libertades.

Artículo 7. Derecho a la Libertad Personal: 1. Toda persona tiene derecho a la libertad y a la seguridad personales; 2 . Nadie puede ser privado de su libertad física, salvo por las causas y en las condiciones fijadas de antemano por las Constituciones Políticas de los Estados Partes o por las leyes dictadas conforme a ellas; 3 . Nadie puede ser sometido a detención o encarcelamiento arbitrarios; 4. Toda persona detenida o retenida debe ser informada de las razones de su detención y notificada, sin demora, del cargo o cargos formulados contra ella; 5. Toda persona detenida o retenida debe ser llevada, sin demora, ante un juez u otro funcionario autorizado por la ley para ejercer funciones judiciales y tendrá derecho a ser juzgada dentro de un plazo razonable o a ser puesta en libertad, sin perjuicio de que continúe el proceso. Su libertad podrá estar condicionada a garantías que aseguren su comparecencia en el juicio; 6. Toda persona privada de libertad tiene derecho a recurrir ante un juez o tribunal competente, a fin de que éste decida, sin demora, sobre la legalidad de su arresto o detención y ordene su libertad si el arresto o la detención fueran ilegales. En los Estados Partes cuyas leyes prevén que toda persona que se viera amenazada de ser privada de su libertad tiene derecho a recurrir a un juez o tribunal competente a fin de que éste decida sobre la legalidad de tal amenaza, dicho recurso no puede ser restringido ni abolido. Los recursos podrán interponerse por sí o por otra persona; 7. Nadie será detenido por deudas. Este principio no limita los mandatos de autoridad judicial competente dictados por incumplimientos de deberes alimentarios.

Artículo 8. Garantías Judiciales: (...) 2. Toda persona inculpada de delito tiene derecho a que se presuma su inocencia mientras no se establezca legalmente su culpabilidad. Durante el proceso, toda persona tiene derecho, en plena igualdad, a las siguientes garantías mínimas: a) derecho del inculpado de ser asistido gratuitamente por el traductor o intérprete, si no comprende o no habla el idioma del juzgado o tribunal; b) comunicación previa y detallada al inculpado de la acusación formulada; c) concesión al inculpado del tiempo y de los medios adecuados para la preparación de su defensa; d) derecho del inculpado de defenderse personalmente o de ser asistido por un defensor de su elección y de comunicarse libre y privadamente con su defensor; e) derecho irrenunciable de ser asistido por un defensor proporcionado por el Estado, remunerado o no según la legislación interna, si el inculpado no se defendiere por sí mismo ni nombrare defensor dentro del plazo establecido por la ley; f) derecho de la defensa de interrogar a los testigos presentes en el tribunal y de obtener la comparecencia, 
Aguirre - El caso Palamara

delitos de incumplimiento de deberes militares, desobediencia y desacato.

En marzo del año 2003, la Comisión, de conformidad con el artículo 50 de la Convención, aprobó el Informe $\mathrm{N}^{\circ} 20 / 03$, mediante el cual recomendó al Estado:

1. Restituir a Humberto Palamara en el goce de sus derechos vulnerados y reintegrar los libros incautados.

2. Reparar adecuadamente a Humberto Palamara Iribarne por las violaciones de los derechos humanos.

3. Impulsar las medidas conducentes para adecuar la legislación interna a las normas de la Convención Americana en materia de libertad de expresión, en particular la derogación del delito de desacato.

En abril de 2003 CEJIL presentó un escrito en el que solicitó a la Comisión que, en el supuesto de que el Estado no cumpliera con las

como testigos o peritos, de otras personas que puedan arrojar luz sobre los hechos; g) derecho a no ser obligado a declarar contra sí mismo ni a declararse culpable, y h) derecho de recurrir del fallo ante juez o tribunal superior.

Artículo 13. Libertad de Pensamiento y de Expresión: 1. Toda persona tiene derecho a la libertad de pensamiento y de expresión. Este derecho comprende la libertad de buscar, recibir y difundir informaciones e ideas de toda índole, sin consideración de fronteras, ya sea oralmente, por escrito o en forma impresa o artística, o por cualquier otro procedimiento de su elección. 2. El ejercicio del derecho previsto en el inciso precedente no puede estar sujeto a previa censura sino a responsabilidades ulteriores, las que deben estar expresamente fijadas por la ley y ser necesarias para asegurar: a) el respeto a los derechos o a la reputación de los demás, o b) la protección de la seguridad nacional, el orden público o la salud o la moral públicas. 3. No se puede restringir el derecho de expresión por vías o medios indirectos, tales como el abuso de controles oficiales o particulares de papel para periódicos, de frecuencias radioeléctricas, o de enseres y aparatos usados en la difusión de información o por cualesquiera otros medios encaminados a impedir la comunicación y la circulación de ideas y opiniones. 4. Los espectáculos públicos pueden ser sometidos por la ley a censura previa con el exclusivo objeto de regular el acceso a ellos para la protección moral de la infancia y la adolescencia, sin perjuicio de lo establecido en el inciso 2. 5. Estará prohibida por la ley toda propaganda en favor de la guerra y toda apología del odio nacional, racial o religioso que constituyan incitaciones a la violencia o cualquier otra acción ilegal similar contra cualquier persona o grupo de personas, por ningún motivo, inclusive los de raza, color, religión, idioma u origen nacional.

Artículo 21. Derecho a la Propiedad Privada: 1. Toda persona tiene derecho al uso y goce de sus bienes. La ley puede subordinar tal uso y goce al interés social. 2. Ninguna persona puede ser privada de sus bienes, excepto mediante el pago de indemnización justa, por razones de utilidad pública o de interés social y en los casos y según las formas establecidas por la ley. 3. Tanto la usura como cualquier otra forma de explotación del hombre por el hombre, deben ser prohibidas por la ley. 
recomendaciones formuladas en su informe, sometiera el caso a conocimiento y fallo de la Corte Interamericana de Derechos Humanos.

En los meses de mayo, junio, agosto, octubre de 2003 y enero de 2004 el Estado de Chile solicitó consecutivas prórrogas para dar respuesta al informe emitido por la Comisión Interamericana y poner así término anticipado al asunto.

El 13 de abril de 2004, después de vencido el último plazo otorgado al Estado de Chile para que presentara su informe sobre las recomendaciones emitidas por la Comisión, sin que dicho evento se hubiere verificado, la Comisión decidió someter el caso al conocimiento de la Corte Interamericana de Derechos Humanos.

En el mes de mayo del mismo año, se notificó al Estado de Chile la demanda interpuesta, se informó sobre el plazo para contestarla y sobre su derecho a designar representante en el proceso. La demanda fue, en definitiva, contestada el 16 de septiembre de 2004.

En mayo de 2005, en la ciudad de Asunción, Paraguay, en la sede de la Corte Suprema de Justicia de ese país, se verificó la audiencia pública en la cual se escucharon los alegatos finales orales sobre el fondo y las eventuales reparaciones. A dicha audiencia comparecieron por la Comisión Interamericana: Evelio Fernández Arévalo, delegado; Eduardo Bertoni, delegado; Víctor H. Madrigal Borloz y Lilly Ching, asesores. Por los representantes del Sr. Palamara: Liliana Tojo, Julieta Di Corleto y Francisco Cox Vial, abogados de CEJIL. Por el Estado de Chile: Amira Esquivel Utreras, Agente; Miguel Ángel González Morales, Agente alterno; y Patricio Aguirre Vacchieri.

\section{El fallo de la Corte}

El 22 de noviembre del año 2005, la Corte Interamericana de Derechos Humanos, dictó sentencia condenatoria contra el Estado Chileno en este caso.

La Corte estimó que las acciones ejecutadas por el Estado, por vía judicial, en contra del Sr. Palamara, fueron constitutivas de actos de censura previa incompatibles con lo consagrado por el artículo 13.2 de la Convención Americana, basado especialmente en que las decisiones adoptadas por los tribunales chilenos impidieron la publicación y divulgación su libro "Ética y servicios de inteligencia", cuestión inaceptable, en especial tras la constatación de que los peritajes requeridos por el Estado eran concluyentes en cuanto a que la información contenida en el libro era accesible por otros medios distintos a aquéllos a los cuales tenía acceso el Sr. Palamara por su situación dentro de una institución castrense. Asimismo, dichas acciones constituyeron una grave restricción a la libertad de pensamiento y expresión, consagrada en la misma disposición. La Corte une estas infracciones a la vulneración del artículo 2 de la Convención 
Aguirre - El caso Palamara

Americana, reafirmando la obligación que pesa sobre los Estados parte de adaptar su legislación interna a fin de dar operatividad y efectividad interna a la Convención suscrita. En este punto en específico declara que si bien el Estado chileno derogó el delito de desacato mediante la dictación de la ley $\mathrm{N}^{\circ} 20.084$, dicha reforma sólo abarcó el tipo establecido en el Código Penal y no las modalidades contenidas Código de Justicia Militar. El hecho que el ordenamiento jurídico siga conteniendo normas desproporcionadas por realizar críticas al funcionamiento de las instituciones estatales y sus miembros, sigue constituyendo una restricción a la libertad de pensamiento y expresión de opiniones válidas y legítimas respecto de la actuación de dichos órganos ${ }^{5}$.

En otro orden, la Corte estimó que la incautación, tanto del material original, de imprenta y editado, como la prohibición de comercialización del texto, constituyó una violación al artículo 21 de la Convención, esto es, su derecho a la propiedad privada. En efecto la Corte sentenció que "tal privación de la propiedad de su obra impidió al Sr. Palamara Iribarne publicar, difundir y comercializar su creación por lo que no pudo continuar con su intención de obtener réditos económicos de dicha publicación y de beneficiarse de la protección que le correspondía por la obra creada".

Sin perjuicio de la gravedad de las infracciones hasta ahora expuestas, constatadas por la Corte, sin duda las más relevantes o más bien, las más sustanciales, son aquellas que dicen relación con la infracción a los artículos 7, 8, 9 y 25 de la Convención, en relación a los artículos 1.1 y 2 de la misma, pues constituyen una directa recriminación a la forma, alcance y legitimidad del sistema de enjuciamiento criminal en tiempo de paz, establecido en el Código de Justicia Militar chileno.

Para llegar a este veredicto respecto a la forma como está consagrada dentro de nuestro derecho interno la justicia militar en tiempos de paz, la Corte recibió el testimonio de destacados juristas nacionales, los cuales le ilustraron tanto sobre la estructura orgánica como sobre el contenido normativo de la judicatura castrense y su alcance 6 .

En pocas palabras puede decirse que la Corte sentenció los mismos reproches que la comunidad académica nacional ha venido denunciando respecto del procedimiento militar en tiempos de paz consagrado en nuestro Código de Justicia Militar?.

\footnotetext{
${ }^{5}$ Cabe tener presente que, la misma observación realizó la Corte respecto a mantener, dentro del Código Penal, el artículo 264, reformado a un tipo de amenazas a la autoridad, reprochando lo ambiguo de su redacción al no delimitar claramente el ámbito típico de la conducta delictiva.

$6 \mathrm{La}$ Corte, en este punto recibió el testimonio en calidad de peritos del abogado Alex Avsolomovich Callejas, la Dra. María Inés Horvitz Lennon, y del profesor Cristián Riego Ramírez.

7 Al respecto cfr., VV.AA., "Justicia Militar y Estado de Derecho", Cuadernos de Análisis Jurídico de la Universidad Diego Portales, serie seminarios No 40, Santiago, 1998; VV.AA., "Hacia una reforma de la Justicia Militar - Delito Militar, Régimen Disciplinario, Competencia y Organización", Cuadernos de Análisis Jurídico de la Universidad Diego Portales, serie
} 
Por un lado establece lo deficitario del sistema para efectos de asegurar el respeto de las garantías judiciales y la protección judicial, ambos institutos consagrados en la Convención, a los cuales no se ajusta la estructura de la justicia castrense chilena.

A este respecto señala que se vulnera el derecho a ser oído por un juez o tribunal competente, puesto que la amplitud de la jurisdicción penal militar, dado el contenido e interpretación que se le asigna a los artículos $5^{\circ}$ y $6^{\circ}$ del Código de Justicia Militar, deviene en que un número no despreciable de civiles queden sujetos al juzgamiento de esta justicia de fuero, haciéndoles aplicables -como en el caso- delitos que por su especialidad el sujeto activo debe ser un militar.

Asimismo, realiza un acabado enjuiciamiento la estructura orgánica de la Justicia Militar, denunciando la vulneración del derecho a ser oído por un juez o tribunal independiente e imparcial. La Corte estimó que "la estructura orgánica y composición de los tribunales (...) supone que, en general, sus integrantes sean militares en servicio activo, estén subordinados jerárquicamente a los superiores a través de la cadena de mando, su nombramiento no depende de su competencia profesional e idoneidad para ejercer las funciones judiciales, no cuenten con garantias suficientes de inamovilidad y no posean una formación jurídica exigible para desempeñar el cargo de juez o fiscales. Todo ello conlleva a que dichos tribunales carezcan de independencia e imparcialidad".

En lo procedimental, la Corte reprocha falencias graves al procedimiento militar en tiempos de paz a fin de asegurar a los enjuciados garantías básicas relacionadas con el derecho a defensa. La falta de publicidad de los procesos, que imposibilita el acceso efectivo al expediente y las pruebas que se recaban, impide una defensa adecuada. La regla del secreto de las actuaciones del sumario es contraria a la garantía de publicidad que debe tener el proceso penal, de acuerdo con lo establecido en el artículo 8.5 de la Convención. A ello se suma que el procedimiento penal militar contiene muy pocas resoluciones que puedan ser revisadas por vía de apelación por los tribunales superiores, lo cual atenta contra las posibilidades de impugnar resoluciones que afectan gravemente derechos fundamentales de los procesados ${ }^{9}$. A juicio de la Corte esta regulación interna viola el artículo 25 de la Convención por cuanto no garantiza el acceso a recursos judiciales efectivos que amparen a los imputados contra las violaciones a sus

publicaciones especiales No 13, Santiago, 2002; Colegio de Abogados de Chile, "Justicia Militar en Chile”, Ed. Conosur Ltda., Santiago, 1990.

8 Esta referencia está hecha a las condenas por desobediencia e incumplimiento de deberes militares de las cuales fuera objeto el demandante.

${ }^{9}$ A este respecto cabe señalar, a modo de ejemplo, la inapelabilidad de resoluciones tan importantes como aquellas referidas a la negativa a recibir testigos de descargo durante el sumario, la negativa a otorgar la libertad provisional durante el sumario antes de 20 días de decretada la prisión preventiva y de la resolución que da por concluido el sumario. 
Aguirre - El caso Palamara

derechos y con ello, a su turno, se incumple la obligación general de respetar y garantizar los derechos y libertades dispuestos en el artículo 1.1 de la Convención.

Asimismo, la Corte observa en el incumplimiento de lo consagrado artículos 7 y 8 de la Convención, la desproporcionalidad de las medidas cautelares adoptadas por la justicia militar chilena, el utilizar la institución de la prisión preventiva como regla general y no como excepción, y en el caso específico, la falta de comunicación de cargos al momento de la detención del Sr. Palamara, concluyendo que el Estado chileno contempla "en su ordenamiento interno normas contrarias a los derechos[,] a la libertad personal y a la presunción de inocencia", sentenciando que con ello "Chile ha incumplido la obligación general de adoptar disposiciones de derecho interno que emana del artículo 2 de la Convención."

\section{Las sanciones y reparaciones dispuestas por la Corte y el estado de su cumplimiento}

Por las infracciones antes detalladas la Corte Interamericana de Derechos Humanos, por unanimidad, dispuso en la parte resolutiva de su fallo que el Estado de Chile debía:

1. Permitir al señor Humberto Antonio Palamara Iribarne la publicación de su libro, así como restituir todo el material del que fue privado.

2. Publicar, en el plazo seis meses, en el Diario Oficial y en otro diario de circulación nacional, por una sola vez, el capítulo relativo a los hechos probados de esta Sentencia, sin las notas al pie de página correspondientes, y la parte resolutiva de la misma.

3. Publicar íntegramente la presente Sentencia en el sitio web oficial del Estado, en el plazo de seis meses.

4. Dejar sin efecto, en el plazo de seis meses, en todos sus extremos, las sentencias condenatorias emitidas en contra del señor Humberto Antonio Palamara Iribarne: la sentencia de 3 de enero de 1995 de la Corte Marcial de la Armada en la Causa Rol No. 471 por el delito de desacato y las sentencias emitidas por dicha Corte Marcial en la Causa No. 464 el 3 de enero de 1997 y por el Juzgado Naval de Magallanes el 10 de junio de 1996 por los delitos de desobediencia e incumplimiento de deberes militares.

5. Debe adoptar todas las medidas necesarias para derogar y modificar, dentro de un plazo razonable, cualesquiera normas internas que sean incompatibles con los estándares internacionales en materia de libertad de pensamiento y de expresión.

6. Adecuar, en un plazo razonable, el ordenamiento jurídico interno a los 
estándares internacionales sobre jurisdicción penal militar, de forma tal que, en caso de que considere necesaria la existencia de una jurisdicción penal militar, ésta debe limitarse solamente al conocimiento de delitos de función cometidos por militares en servicio activo. Por lo tanto, el Estado debe establecer, a través de su legislación, límites a la competencia material y personal de los tribunales militares, de forma tal que, en ninguna circunstancia, un civil se vea sometido a la jurisdicción de los tribunales penales militares.

7. Garantizar el debido proceso en la jurisdicción penal militar y la protección judicial respecto de las actuaciones de las autoridades militares.

8. Pagar al señor Humberto Antonio Palamara Iribarne, en el plazo de un año, por concepto de indemnización por daño material las cantidades fijadas en los párrafos 239, 242 y 243 de la Sentencia, en los términos de los párrafos 261 a 267 de la misma. (sueldo: U\$ 8.400; lucro cesante U\$ 11.000; U\$ 4.000 daño emergente).

9. Pagar al señor Humberto Antonio Palamara Iribarne, en el plazo de un año, por concepto de la indemnización por daño inmaterial la cantidad fijada en el párrafo 248 de la Sentencia, en los términos de los párrafos 261 a 267 de la misma. (U\$ 30.000).

10. Pagar al señor Humberto Antonio Palamara Iribarne, en el plazo de un año, por concepto de las costas y gastos la cantidad fijada en el párrafo 260 de la Sentencia, en los términos de dicho párrafo. (U\$4.000).

La Corte finaliza disponiendo que, ésta supervisará el cumplimiento íntegro de la Sentencia, y dará por concluido el presente caso una vez que el Estado haya dado cabal cumplimiento a lo dispuesto en la misma. Impone asimismo la obligación de presentar ante la Corte un informe sobre las medidas adoptadas para dar cumplimiento a lo sentenciado, lo cual debía realizar en el plazo de un año a contar de la notificación del fallo.

El 15 de enero del año 2007, el Estado de Chile ingresó a la Secretaría de la Corte Interamericana escrito mediante el cual remitió informe sobre las medidas adoptadas para dar cumplimiento al fallo tanto respecto al fondo del mismo, como a las reparaciones dispuestas ${ }^{10}$.

En dicho informe el Estado declara que "a poco más de un año de la notificación de la sentencia, puede señalar que ésta se ha cumplido en su mayor parte".

En efecto, a la fecha, el Estado ha resarcido al Sr. Palamara de todos los perjuicios económicos causados por las acciones desplegadas que infringieron su

\footnotetext{
${ }^{10}$ Con anterioridad, el 17 de febrero y 14 de diciembre de 2006, el Estado informó el cumplimiento parcial de algunas de las reparaciones decretadas por la Corte.
} 
Aguirre - El caso Palamara

derecho a la propiedad privada. Asimismo ha permitido la publicación del libro, el cual fue en definitiva editado y publicado a través de la imprenta de la propia Armada de Chile. Realizó las publicaciones correspondientes, tanto en el Diario Oficial y La Nación, como en la página web del Ministerio de Relaciones Exteriores.

Lamentablemente, a la fecha el Estado no ha dado cumplimiento a lo sustancial de la sentencia dictada por la Corte, esto es, realizar las modificaciones necesarias para efectos adecuar la legislación interna a los estándares internacionales sobre jurisdicción militar, garantizar el debido proceso y la protección judicial en dicho marco procedimiental y modificar todas aquellas normas que aún están vigentes dentro de nuestro ordenamiento y que atentan contra la libertad de pensamiento y expresión ${ }^{11}$.

Sobre este punto el Estado informó que con fecha 26 de enero de 2006 se creó una Comisión Especial encargada de realizar y proponer una reforma integral a la justicia penal militar. En su presentación indica que dicha Comisión estaría integrada por representantes de los Ministerios del Interior, Relaciones Exteriores, Justicia y de las Fuerzas Armadas y de Orden.

Sin embargo, a la fecha -más de un año de su constitución- la Comisión no sólo no ha generado un documento que sea conocido sobre la materia, sino que además, si bien aparece en la página del Ministerio de Justicia como proyectos pendientes, el link respectivo carece de toda información respecto a los avances de la Comisión, de la cual -al menos en el ambiente académico y de cara a la ciudadanía- ni siquiera se conoce la individualización de los miembros que la conforman.

La gravedad de los reproches atribuidos por la Corte a la estructura de la Justicia Militar chilena, dejan de manifiesto la necesidad de que el Estado adopte de manera seria y urgente las medidas necesarias a objeto de avanzar hacia una reforma sustancial de la judicatura castrense, a fin de adecuarla a los parámetros básicos requeridos por la Convención para efectos de impartir justicia criminal en el marco y conforme a los estándares de un Estado de Derecho.

\footnotetext{
${ }_{11} \mathrm{Al}$ respecto cabe señalar que el Estado informó que el Poder Ejecutivo se encuentra estudiando la posibilidad de enviar un proyecto de ley que aclare o modifique los alcances del artículo 264 del Código Penal. Respecto al delito de desacato aún vigente en Código de Justicia Militar, éste constituye un tema a abordarse en la Comisión que estudiará una reforma integral a la Justicia Militar chilena.
} 